\title{
Comparison of pathways for biodegradation of monomethyl sulphate in Agrobacterium and Hyphomicrobium species
}

\author{
Timothy P. Higgins, Jason R. SNape and Graham F. White* \\ Department of Biochemistry, University of Wales College of Cardiff, PO Box 903, Cardiff CF1 1ST, UK
}

(Received 7 June 1993; revised 26 July 1993; accepted 4 August 1993)

\begin{abstract}
Different mechanisms have been proposed previously for the biodegradation of monomethyl sulphate (MMS) in Agrobacterium sp. and Hyphomicrobium sp. Sulphate liberation from MMS in Agrobacterium sp. M3C was previously shown to be $\mathrm{O}_{2}$-dependent, whereas in several Hyphomicrobium spp. the initiating step has been considered hitherto to be hydrolytic and catalysed by methyl sulphatase. In the present study, Agrobacterium and Hyphomicrobium strains were compared for their ability to oxidize MMS and its potential metabolites in the oxygen electrode. MMS-grown Agrobacterium sp. M3C and Hyphomicrobium sp. MS223 oxidized MMS with consumption of $0.5 \mathrm{~mol} \mathrm{O}_{2}$ per mol of substrate, but they were unable to oxidize methanol. By repeatedly challenging MMS-grown Hyphomicrobium with MMS in the electrode chamber, all the $\mathrm{O}_{2}$ in the electrode became exhausted, at which point $\mathrm{SO}_{4}^{2-}$ liberation stopped although excess $\mathrm{MMS}$ was available. $\mathrm{SO}_{4}^{2-}$ release resumed immediately when $\mathrm{O}_{2}$ was re-admitted to the electrode chamber. Thus liberation of $\mathrm{SO}_{4}^{2-}$ from $\mathrm{MMS}$ in the oxygen electrode was dependent on the continuing availability of $\mathrm{O}_{2}$. Hyphomicrobium $\mathrm{sp}$. MS223 therefore closely resembled Agrobacterium sp. $\mathrm{M3C}$ in its obligatory requirement for $\mathrm{O}_{2}$ in MMS degradation. Unlike Agrobacterium sp. M3C, Hyphomicrobium sp. MS223 was able to grow on methanol and methanol-grown cells oxidized methanol ( $0.5 \mathrm{~mol} \mathrm{O}_{2}$ per mol of substrate) but not MMS. Cyclopropanol, an inhibitor of methanol dehydrogenase, abolished oxidation of methanol by methanol-grown Hyphomicrobium sp. MS223 but did not affect oxidation of MMS by MMS-grown cells. Thus Hyphomicrobium sp. MS223 expresses enzymes for oxidation of methanol when needed for growth on this compound, but not when grown on MMS. These results are consistent with the absence of methanol from the pathway for biodegradation of MMS by Hyphomicrobium sp. MS223 and suggest that in at least some Hyphomicrobium spp. an oxidative mechanism initiates biodegradation.
\end{abstract}

\section{Introduction}

Monomethyl sulphate (MMS) enters the environment as a component in fly-ash from coal- and oil-burning power stations (Eatough et al., 1981; Lee et al., 1980) and as a waste byproduct of the use of dimethyl sulphate in industrial methylation processes (Ghisalba et al., 1985a). Dialkyl sulphates are very reactive and transfer the first alkyl group readily to acceptors such as $\mathrm{OH}$ and $\mathrm{NH}$ functional groups, but the residual monoalkyl sulphates are (relatively) much more stable (Heiner et al., 1962). Studies of the bacterial biodegradation of MMS are thus pertinent to assessing its environmental impact and acceptability, and to the development of methods for industrial waste-treatment which might replace current methods such as incineration (Ghisalba et al., 1985a).

* Author for correspondence. Tel. +44 222874188 ; fax +44222 874116; e-mailwhitegf1@uk.ac.cardiff.

Abbreviation: MMS, monomethyl sulphate.
Mechanisms of bacterial biodegradation of MMS are also of particular fundamental interest because this compound lies at the interface between two groups of organic compounds which separately have attracted considerable attention and for which metabolic pathways are quite distinct. On the one hand, MMS is a $\mathrm{C}_{1}$ compound and thus a potential addition to the list of compounds that support growth of methylotrophic organisms (Anthony, 1982; Higgins et al., 1980; Large, 1983). On the other hand it is a sulphate ester, in fact the shortest in the homologous series of linear primary alkyl sulphates, the longer of which are surfactants. Much is now known about the biochemical mechanisms and enzymology of alkyl sulphate biodegradation. Longchain esters undergo hydrolysis catalysed by alkyl sulphatases in Pseudomonas sp. (Bartholomew et al., 1978; Bateman et al., 1986; Cloves et al., 1980; Dodgson \& White, 1983; Dodgson et al., 1982; Matcham et al., $1977 a, b$; Shaw et al., 1980; White \& Russell, 1993) but these enzymes cease to function when the alkyl chain 
length falls below $\mathrm{C}_{5}$. A coryneform species has been shown recently to produce an alkyl sulphatase restricted to primary esters in the $\mathrm{C}_{3}-\mathrm{C}_{7}$ chain length range (White \& Matts, 1992). The degradation of the shortest secondary alkyl sulphate, propyl 2-sulphate, is initiated by oxidation of a methyl group to lactate 2-sulphate before a specific D-lactate-2-sulphatase removes inorganic sulphate (Crescenzi et al., 1984, 1985).

A methyl sulphatase has been reported to initiate biodegradation of MMS in Hyphomicrobium spp. (Ghisalba et al., 1985 a, 1986; Ghisalba \& Kuenzi, 1983; Schar \& Ghisalba, 1985), based on the detection of methanol in culture fluids during growth on the ester and on the ability of Hyphomicrobium spp. to produce methanol dehydrogenase (Schar et al., 1985). In contrast, the pathway proposed for MMS biodegradation in Agrobacterium sp. $\mathrm{M} 3 \mathrm{C}$ is initiated by monooxygenasecatalysed conversion of the ester to formaldehyde without formation of methanol. This mechanism was based on results of oxygen electrode studies and on the dependence of $\mathrm{SO}_{4}^{2-}$ release on the availability of $\mathrm{O}_{2}$. The present study was undertaken to make a closer comparison of the pathways for MMS biodegradation in Hyphomicrobium and Agrobacterium species.

\section{Methods}

Chemicals. Except where otherwise stated, all chemicals were of analytical grade supplied by Merck (BDH) or Sigma. Noble agar was obtained from Difco, and helium from British Oxygen Corporation. MMS was prepared from dimethyl sulphate (Fluka) as described elsewhere (Davies et al., 1990). Elemental composition determined by combustion analysis was carbon, $8.06 \%$ (theoretical $7.99 \%$ ), and hydrogen, $1.99(2.01 \%)$, indicating a purity of $99 \%$. The infra-red spectrum contained strong absorption bands at $1210 \mathrm{~cm}^{-1}$ and $770-810 \mathrm{~cm}^{-1}$ corresponding to vibrational modes in $\mathrm{S}-\mathrm{O}$ and $\mathrm{C}-\mathrm{O}-\mathrm{S}$ bonds of $\mathrm{R}-\mathrm{O}-\mathrm{SO}_{3}^{-}$(Lloyd et al., 1961). Spectra lacked absorption bands at $3320 \mathrm{~cm}^{-1}$ (unsubstituted hydroxyl groups) as would be found in methanol. The natural-abundance ${ }^{13} \mathrm{C}$-NMR spectrum $(100 \cdot 6 \mathrm{MHz}$, Brucker Aspect 2000) of MMS gave a single resonance (58.2 p.p.m.) with no sign of resonance at 50 p.p.m. characteristic of methanol. HPLC ion chromatography of the sample (see below) yielded a single major peak, and contamination of the sample by $\mathrm{SO}_{4}^{2-}$ so low as to be indistinguishable from that in the Type I water used to prepare the sample.

Cyclopropanol, as a $4 \mathrm{~mm}$ solution in water, was kindly supplied by Professor I. Ochura, Department of Bioengineering, Tokyo Institute of Technology, Japan.

Where samples of incubation mixtures were to be analysed by ion chromatography, the water used for the preparation of all solutions was Type 1 deionized $18 \mathrm{M} \Omega, 0.22 \mu \mathrm{m}$-filtered water from a Millipore Q50 water-purification unit.

Organisms and culture conditions. Agrobacterium sp. strain M3C (NCIMB 13265) was isolated previously in Cardiff for its ability to grow on MMS (Davies et al., 1990) as sole source of carbon. Hyphomicrobium sp. strain MS223 (NRRL-B-12570, Agricultural Research Culture Collection, Preoria, Illinois 61604, USA) was originally isolated in Basel, also for its ability to utilize MMS as sole source of carbon (Ghisalba \& Kuenzi, 1983). A culture of this isolate was kindly supplied by Dr O. Ghisalba, CIBA Geigy Corporation,
Basel, Switzerland. Axenic culture was established by repeated subculturing on minimal-medium agar plates containing MMS as sole source of carbon.

For the present study culture media for both Agrobacterium and Hyphomicrobium spp. contained, per litre of distilled water: $\mathrm{NH}_{4} \mathrm{NO}_{3}$, $2.0 \mathrm{~g} ; \quad \mathrm{Na}_{2} \mathrm{HPO}_{4}, \quad 1.4 \mathrm{~g} ; \quad \mathrm{KH}_{2} \mathrm{PO}_{4}, 0.6 \mathrm{~g} ; \quad \mathrm{MgSO}_{4} .7 \mathrm{H}_{2} \mathrm{O}, 0.2 \mathrm{~g}$; $\mathrm{CaCl}_{2} .2 \mathrm{H}_{2} \mathrm{O}, 0.01 \mathrm{~g} ; \mathrm{FeSO}_{4} .7 \mathrm{H}_{2} \mathrm{O}, 0.001 \mathrm{~g}$; and $1 \mathrm{ml}$ of trace elements solution (Ghisalba \& Kuenzi, 1983). Trace elements solution contained $20 \mathrm{mg}$ each of $\mathrm{Na}_{2} \mathrm{MoO}_{4} \cdot 2 \mathrm{H}_{2} \mathrm{O}, \mathrm{Na}_{2} \mathrm{~B}_{4} \mathrm{O}_{7} .10 \mathrm{H}_{2} \mathrm{O}, \mathrm{ZnSO}_{4} .7 \mathrm{H}_{2} \mathrm{O}$, $\mathrm{MnSO}_{4} \cdot \mathrm{H}_{2} \mathrm{O}$ and $\mathrm{CuSO}_{4} \cdot 5 \mathrm{H}_{2} \mathrm{O}$ per litre of distilled water. This basal salts medium ( $45 \mathrm{ml}$ in $100 \mathrm{ml}$ Erlenmeyer flasks) was autoclaved at $0.1 \mathrm{MPa}, 121^{\circ} \mathrm{C}$ for $20 \mathrm{~min}$. MMS or methanol $(0.33 \mathrm{M})$ dissolved in $1 \mathrm{M}$-phosphate buffer $\mathrm{pH} \mathrm{7,} \mathrm{was} \mathrm{filter-sterilized} \mathrm{and} \mathrm{added} \mathrm{aseptically}$ to the basal salts medium to give a final concentration of $33 \mathrm{~mm}$. The additional phosphate buffer $(0.1 \mathrm{~m}$ final concentration) was necessary to accommodate significant release of $\mathrm{H}^{+}$during utilization of MMS (Ghisalba et al., 1985a; Ghisalba \& Kuenzi, 1983) and other short chain sulphate esters (Crescenzi et al., 1985). Cultures were incubated at $30^{\circ} \mathrm{C}$ in an orbital shaker ( 150 r.p.m.) and growth was monitored by culture optical density $\left(\mathrm{OD}_{420}\right.$, LKB-Pharmacia Novaspek II spectrophotometer). Stock cultures were maintained on slopes of the same medium solidified with $1.5 \%(\mathrm{w} / \mathrm{v})$ Noble agar.

Preparation of cell suspensions. Cells at the end of the exponential phase of growth $\left(\mathrm{OD}_{420}\right.$ in the range of $\left.0.4-0.7\right)$ were harvested by centrifugation $\left(90000 \boldsymbol{g}_{a v}\right.$. min, GS3 rotor in a Sorval RC-5B refrigerated centrifuge), washed at least four times and resuspended in phosphate buffer $\mathrm{pH}$, usually to one-tenth of the original culture volume.

Analysis of $\mathrm{MMS}$ and $\mathrm{SO}_{4}^{2-}$. MMS and $\mathrm{SO}_{4}^{2-}$ were analysed by ion chromatography with suppressed conductivity detection. Samples were individually injected onto an Omnipac PAX-500 column installed in a DX300 series ion chromatography system (Dionex). The column was eluted isocratically at $1 \mathrm{ml} \mathrm{min}{ }^{-1}$ with eluent containing $30 \mathrm{~mm}$-sodium hydroxide (low in carbonate) and $5 \%(\mathrm{v} / \mathrm{v})$ methanol (HiPerSolv grade) which was initially degassed and stored under helium, to prevent the elevation of carbonate ions from dissolved $\mathrm{CO}_{2}$ and the production of gas bubbles in the HPLC detector. Peak areas were integrated using a Spectra Physics 4400 integrator and were corrected for any temperature drift during the elution. The correction factor for this particular equipment was $1.7 \%$ per ${ }^{\circ} \mathrm{C}$, and all values were adjusted to correspond to $25^{\circ} \mathrm{C}$. Integrated temperature-corrected peak areas were then converted to molarity of $\mathrm{MMS}$ and $\mathrm{SO}_{4}^{2-}$ using separately determined calibration curves.

$\mathrm{O}_{2}$-uptake measurements. Agrobacterium sp. strain M3C grown on MMS or Hyphomicrobium sp. strain MS223 grown on MMS or on methanol were harvested at the end of the exponential phase, washed in $0.1 \mathrm{M}$-phosphate buffer $\mathrm{pH} \mathrm{7,} \mathrm{and} \mathrm{resuspended} \mathrm{at} \mathrm{10-fold} \mathrm{con-}$ centration as described above. Samples of the concentrated cell suspension $(0.5 \mathrm{ml})$ were introduced into a Clark-type oxygen electrode (Rank Brothers) containing $2.7 \mathrm{ml} 0.1 \mathrm{M}$-phosphate buffer equilibrated with air at $30^{\circ} \mathrm{C}$. The rate of $\mathrm{O}_{2}$-uptake of the cells was recorded for $5 \mathrm{~min}$ to establish a basal rate, before addition of concentrated solutions of MMS or other test compounds (typically $20 \mu \mathrm{l}, 200 \mathrm{nmol}$ ). The electrode was calibrated with NADH as described by Robinson \& Cooper (1970).

$\mathrm{O}_{2}$-uptake and liberation of $\mathrm{SO}_{4}^{2-}$. Water used for the preparation of all solutions in these experiments was Type 1 deionized $18 \mathrm{M} \Omega$, $0.22 \mu \mathrm{m}$-filtered water. Agrobacterium sp. strain M3C and Hyphomicrobium sp. strain MS223 were harvested at the end of the exponential phase and washed in $5 \mathrm{~mm}$-phosphate buffer $\mathrm{pH} 7$. Cells were resuspended in one-tenth of the original culture volume, and $1 \mathrm{ml}$ aliquots of the resuspensions were added to $2.7 \mathrm{ml}$ of aerated $5 \mathrm{~mm}-$ phosphate buffer in the oxygen electrode. The rate of $\mathrm{O}_{2}$-uptake was recorded for a period prior to the addition of MMS to establish the 


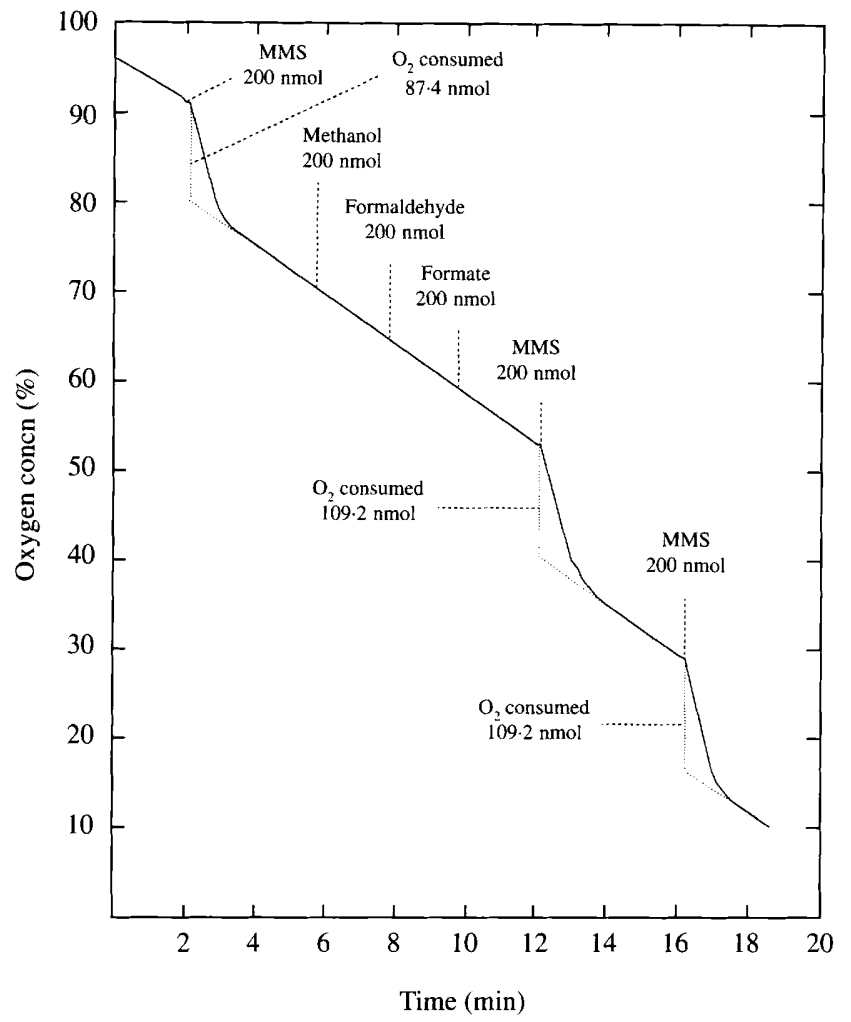

Fig. 1

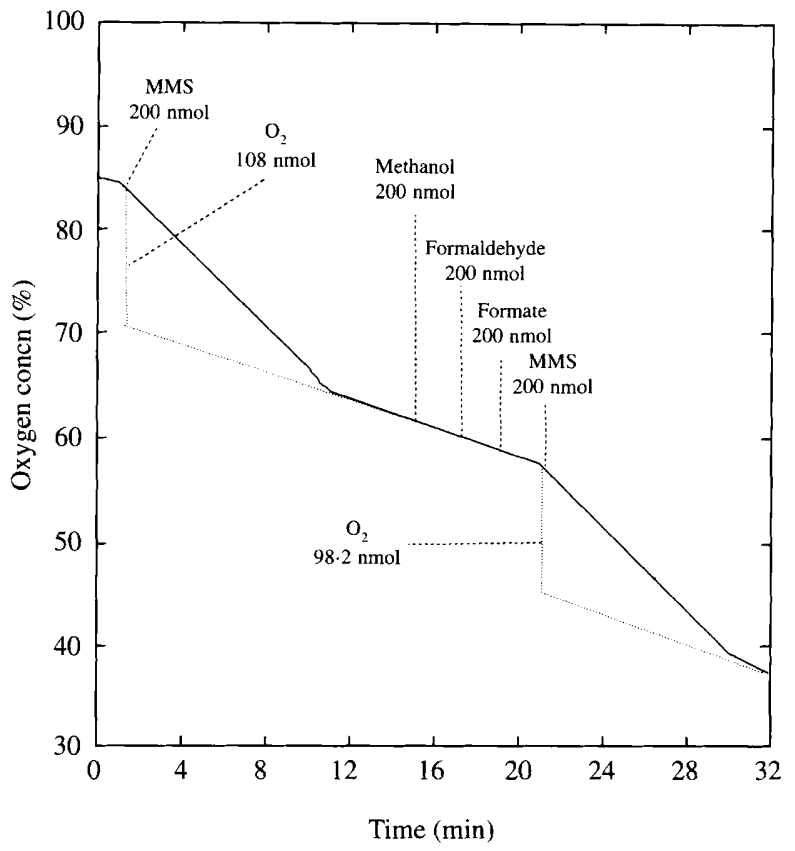

Fig. 2

Fig. 1. $\mathrm{O}_{2}$-uptake by MMS-grown cells of Agrobacterium sp. M3C. Substrates ( $200 \mathrm{nmol}$ aliquots) were added at the indicated points without allowing the entry of $\mathrm{O}_{2}$ into the electrode chamber.

Fig. 2. $\mathrm{O}_{2}$-uptake by MMS-grown cells of Hyphomicrobium sp. MS223. Substrates ( $200 \mathrm{nmol}$ aliquots) were added at the indicated points without allowing the entry of $\mathrm{O}_{2}$ into the electrode chamber.

basal rate of $\mathrm{O}_{2}$-uptake. MMS ( $\left.50 \mu 1,670 \mathrm{nmol}\right)$ was then added to the reaction chamber. At intervals both before and after addition of MMS, aliquots $(50 \mu \mathrm{l})$ were withdrawn from the electrode chamber without the admission of atmospheric $\mathrm{O}_{2}$ by using a microsyringe. Each aliquot was immediately diluted $(40 \mu \mathrm{l}$ to $1 \mathrm{ml})$ with water, filtered through a $0.22 \mu \mathrm{m}$ Anatop filter (Whatman) and frozen at $-20{ }^{\circ} \mathrm{C}$ to await subsequent analysis for MMS and $\mathrm{SO}_{4}^{2-}$ contents.

When the $\mathrm{O}_{2}$-uptake rate had returned to the basal rate, a further aliquot of MMS was added to the chamber and samples were taken as before. Previous experiments had shown that the amount of MMS which had been added in these two additions was enough to make the reaction chamber anaerobic. With the reaction chamber in this state, two further aliquots of MMS $(50 \mu 1,670 \mathrm{nmol})$ were added, and samples taken as before. The stopper of the oxygen electrode was then removed to allow atmospheric $\mathrm{O}_{2}$ to dissolve into the solution. When the $\mathrm{O}_{2}$ concentration reached about $80 \%$ saturation the stopper was replaced and a further four samples were taken for analysis.

\section{Results}

Both Agrobacterium sp. strain $\mathrm{M} 3 \mathrm{C}$ and Hyphomicrobium sp. strain MS223 grew substantially (maximum $\mathrm{OD}_{420}=1.2$ ) and at about the same rate (doubling time approximately $8 \mathrm{~h}$ ) on $33 \mathrm{~mm}-\mathrm{MMS}$. However, only Hyphomicrobium sp. strain MS223 was capable of growth on methanol (33 mM), with a doubling time of about $6 \mathrm{~h}$ and final $\mathrm{OD}_{420}$ of $1 \cdot 5$.

Agrobacterium sp. strain M3C grown on MMS (Fig. 1) and Hyphomicrobium sp. strain MS223 also grown on MMS (Fig. 2) each utilized about $1 \mathrm{~mol} \mathrm{O}_{2}$ for every 2 mol MMS added to the oxygen electrode chamber. When potential $\mathrm{C}_{1}$ intermediates of the metabolic pathway were added to the electrode chamber (viz. methanol, formaldehyde and formate), the rate of oxygen uptake did not change from the basal rate for either isolate. In both organisms, the MMS-stimulated $\mathrm{O}_{2}$ uptake was not affected by the presence of cyclopropanol ( $0.4 \mathrm{~mm}$ final concentration), a known inhibitor of PQQ (pyrroloquinoline quinone)-dependent methanol dehydrogenase (Dijkstra et al., 1984; Frank et al., 1989; Shimoda \& Okura, 1991).

$\mathrm{O}_{2}$-uptake by methanol-grown Hyphomicrobium sp. strain MS223 showed no deflection from the basal rate when MMS was added to the oxygen electrode chamber (Fig. 3). However, when the growth substrate, methanol, was added to the reaction chamber there was a sharp acceleration of $\mathrm{O}_{2}$-uptake. The additional utilization of $\mathrm{O}_{2}$ was equivalent to about $1 \mathrm{~mol} \mathrm{O}_{2}$ utilized for every 


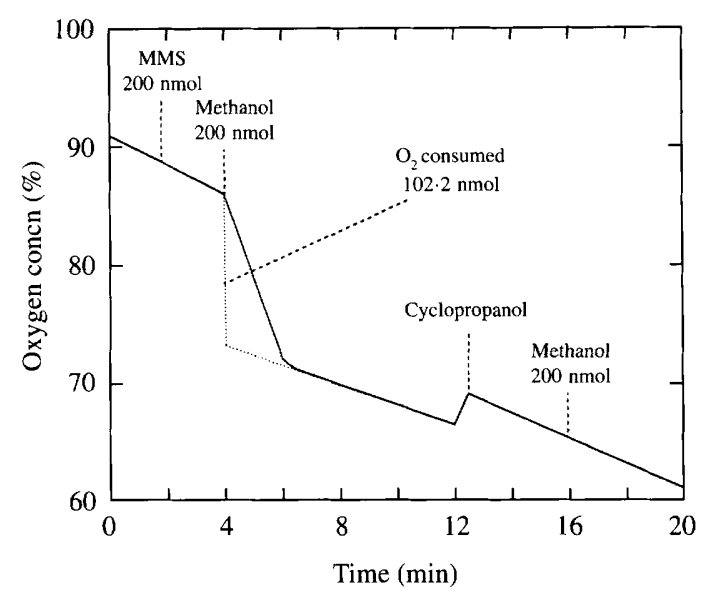

Fig. 3. $\mathrm{O}_{2}$-uptake by methanol-grown cells of Hyphomicrobium sp. MS223. Substrates ( $200 \mathrm{nmol}$ aliquots) were added at the indicated points without allowing the entry of $\mathrm{O}_{2}$ into the electrode chamber. Cyclopropanol was added to give a final concentration of $0.4 \mathrm{~mm}$.

2 mol methanol added to the chamber. The methanolstimulated $\mathrm{O}_{2}$-uptake was abolished when cyclopropanol $(0.4 \mathrm{~mm}$ final concentration) was added (Fig. 3).

Fig. 4 shows $\mathrm{O}_{2}$-uptake when serial additions of MMS were made to MMS-grown Hyphomicrobium sp. strain MS223. Simultaneously, the oxygen electrode chamber was sampled and analysed for residual MMS and $\mathrm{SO}_{4}^{2-}$ production. After the first addition, MMS was converted almost stoichiometrically to $\mathrm{SO}_{4}^{2-}$, with the expected consumption of $0.5 \mathrm{~mol} \mathrm{O}_{2}$ per mol of ester added. After a second addition $(29 \mathrm{~min})$, the oxygen electrode became depleted of $\mathrm{O}_{2}(42 \mathrm{~min})$ and after this point relatively little conversion of MMS to $\mathrm{SO}_{4}^{2-}$ occurred, despite continued presence of MMS from further additions at 51 and $75 \mathrm{~min}$. Biotransformation of $\mathrm{MMS}$ to $\mathrm{SO}_{4}^{2-}$ resumed at an appreciable rate only when $\mathrm{O}_{2}$ was re-admitted to the electrode chamber ( $96 \mathrm{~min}$ ).

\section{Discussion}

Two possible metabolic pathways for the degradation of monomethyl sulphate have been formulated (Fig. 5). Davies et al. (1990) proposed that the initial step in the degradation of MMS involved a monooxygenase enzyme, which oxidized MMS to methanediol monosulphate via a 4-electron transfer. The proposed mechanism showed that the electrons were derived equally from NADH and MMS and, because oxidation of NADH is subsumed in the basal rate, the addition of MMS to cells was expected to increase demand for electrons by $2 e^{-}$per molecule added. The methanediol sulphate produced from the initial step decomposed spontaneously to form $\mathrm{SO}_{4}^{2-}$ and formaldehyde, a central intermediary metabolite in $\mathrm{C}_{1}$ metabolism (Attwood \&
Quayle, 1984). The formaldehyde can either be assimilated by the organism via the serine pathway or oxidized to $\mathrm{CO}_{2}$ via formate in sequential 2-electron transfers.

The alternative proposed pathway (Ghisalba \& Kuenzi, 1983) involved the hydrolytic cleavage of MMS by a sulphatase enzyme to yield methanol and $\mathrm{SO}_{4}^{2-}$. The methanol was then oxidized to formaldehyde via a 2electron step by a PQQ-dependent methanol dehydrogenase enzyme (Schar et al., 1985). The formaldehyde produced by this pathway then undergoes the same fate as that from the monooxygenase pathway.

The present study has shown that Agrobacterium sp. strain M3C grown on MMS required $0.5 \mathrm{~mol} \mathrm{O}_{2}$ per mol MMS added to resting cells in the oxygen electrode, i.e. a 2-electron transfer for each molecule of MMS. Bearing in mind that these cells did not oxidize exogenously added formaldehyde or formate, the 2electron transfer was consistent with the operation of either the monooxygenase pathway (2-electron transfer prior to sulphate release) or the hydrolytic pathway (2-electron transfer after sulphate release) up to the formaldehyde stage. Previous work (Davies et al., 1990) has established that sulphate release from MMS in Agrobacterium sp. strain $\mathrm{M} 3 \mathrm{C}$ is dependent upon the immediate availability of $\mathrm{O}_{2}$. This, together with the inability of Agrobacterium sp. strain M3C to grow on methanol and the inability of MMS-grown cells to oxidize methanol, argues in favour of the oxygenolytic pathway (Fig. 5) for degradation of MMS in this isolate.

Hyphomicrobium sp. strain MS223 resembles Agrobacterium sp. strain M3C in its capacity for growth on MMS and its ability to oxidize MMS in the oxygen electrode (2-electron transfer per molecule of MMS, Fig. 2). Moreover, the conversion of MMS to $\mathrm{SO}_{4}^{2-}$ only occurred when molecular $\mathrm{O}_{2}$ was freely available (Fig. 4). As with Agrobacterium sp. strain M3C, Hyphomicrobium sp. strain MS223 grown on MMS was unable to oxidize methanol in the oxygen electrode. The similarity in results for the two strains argues for the oxygenolytic cleavage mechanism in both cases.

Hyphomicrobium sp. strain MS223 and Agrobacterium sp. strain $\mathrm{M} 3 \mathrm{C}$ differed significantly in the ability of the former, but not the latter, to grow on methanol. Methanol-grown cells of Hyphomicrobium sp. strain MS223 were capable of oxidizing methanol in the oxygen electrode $\left(0.5 \mathrm{~mol} \mathrm{O}_{2}\right.$ per mol methanol). This 2-electron transfer corresponds to oxidation of methanol to formaldehyde but no further, and is consistent with failure of exogenous formaldehyde or formate to elicit a response from the same cells in the electrode. Methanol oxidation by methanol-grown cells was inhibited by cyclopropanol, a known inhibitor of PQQ-dependent methanol dehydrogenase (Dijkstra et al., 1984; Frank et al., 1989; Shimoda \& Okura, 1991). These results are in agreement with observations of $\mathrm{O}$. Ghisalba's group 


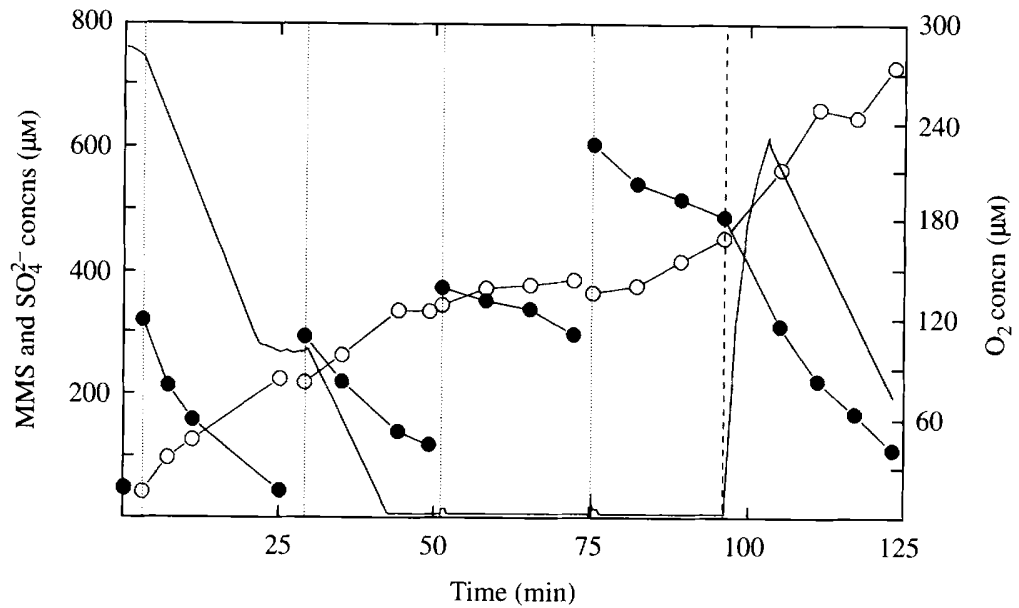

Fig. 4. Simultaneous $\mathrm{O}_{2}$-uptake and desulphation of MMS by Hyphomicrobium sp. MS223. Additions of MMS $(50 \mu \mathrm{l}, 670 \mathrm{nmol})$ were made at the times indicated by the vertical dotted lines ( 3 , 29,51 and $75 \mathrm{~min}$ ). The electrode chamber was opened to readmit oxygen at the vertical dashed lined ( $96 \mathrm{~min}$ ), and closed again at $102 \mathrm{~min}$. $\mathrm{O}_{2}$ concentration;, $\mathrm{MMS} ; \mathrm{O}, \mathrm{SO}_{4}^{2-}$.

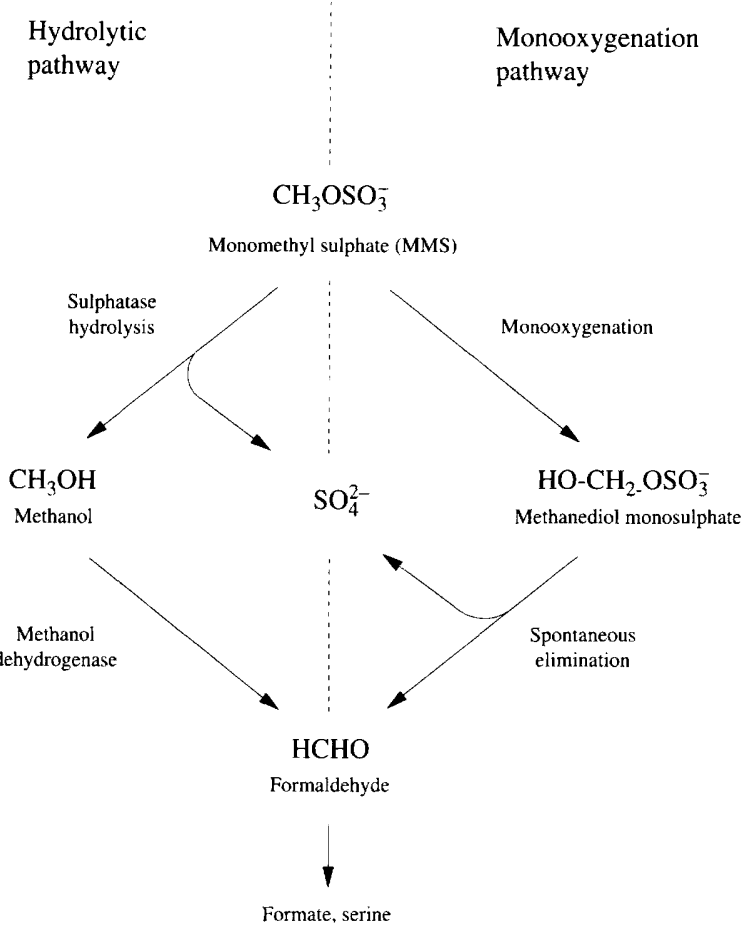

Fig. 5. Hydrolytic and oxidative mechanisms for bacterial biodegradation of MMS

(Ghisalba et al., 1985a,b; Ghisalba \& Kuenzi, 1983; Schar et al., 1985) for growth on, and oxidation of, methanol. Evidently Hyphomicrobium sp. strain MS223 can synthesize enzyme(s) for the oxidation of methanol when the situation demands it (e.g. growth on methanol as sole source of carbon). However, in our hands the capacity to oxidize methanol was not expressed during growth on MMS. Moreover, although methanol oxidation by methanol-grown cells was inhibited by cyclopropanol, MMS oxidation by MMS-grown cells was unaffected by cyclopropanol. This provides strong evidence for the absence of methanol from the catabolic pathway for MMS, and thus lends further weight to the operation of the oxygenolytic pathway (Fig. 5) rather than the hydrolytic pathway proposed hitherto (Ghisalba et al., 1985a, 1986; Ghisalba \& Kuenzi, 1983; Schar \& Ghisalba, 1985).

Our data for Hyphomicrobium sp. MS223 are thus inconsistent with a sulphatase-initiated metabolism of MMS. The claim for the existence of a hydrolytic pathway in a group of MMS-degrading Hyphomicrobium spp. has been repeated in several papers (Ghisalba et al., 1985a, 1986; Ghisalba \& Kuenzi, 1983; Schar \& Ghisalba, 1985) but the data supporting the generalization are limited. Methanol was detected (Ghisalba et al., 1985a) in stirred-tank reactors in which MMS was used to support growth of Hyphomicrobium sp. MS72 (NRRL-B-12573). It may be significant that, in several of its biochemical characteristics, this particular isolate was different from other MMS degraders, including Hyphomicrobium sp. MS223 used in the present study (Ghisalba et al., 1985b; Ghisalba \& Kuenzi, 1983). Thus, while the conclusion that methanol was formed via a methyl sulphatase may be valid for Hyphomicrobium sp. MS72, the extrapolation to the other strains of Hyphomicrobium spp. is difficult to sustain, at least on the basis of published data. Hyphomicrobium sp. MS223 does synthesize a methanol dehydrogenase (Schar et al., 1985) but this was produced during growth on methanol. To the best of our knowledge there is no published data to indicate production of methanol dehydrogenase during growth on pure MMS.

Location of the MMS-degrading activity in the cellmembrane of Hyphomicrobium spp. has been noted (Ghisalba et al., 1986), and this location has hindered attempts to purify and characterize the enzyme. In contrast, all alkyl sulphatases studied to date are soluble and located either in the cytosol or in the periplasmic space (Dodgson et al., 1982; Thomas et al., 1988). On the other hand, some monooxygenases are known to be 
located in the cell membrane (Large, 1983; Fox et al., 1990; Pilkington \& Dalton, 1990). Thus in terms of cellular localization the MMS-degrading enzyme is closer to the monooxygenases than to sulphatases. Efforts are currently underway to establish and compare MMSdegrading activities in cell-free extracts of Agrobacterium and Hyphomicrobium.

T. P. Higgins is grateful to the SERC Biotechnology Directorate for the award of a studentship. We thank Dr O. Ghisalba, CIBA-GEIGY, Basel, for providing cultures of Hyphomicrobium sp. MS223, Professor I. Ochura, Tokyo Institute of Technology, for supplying cyclopropanol, and Dr M. J. E. Hewlins, Department of Chemistry, University of Wales Cardiff, for NMR analyses.

\section{References}

Anthony, C. (1982). The Biochemistry of Methylotrophs. London: Academic Press.

AtTwood, M. \& Quayle, J. R. (1984). Formaldehyde as a central intermediary metabolite of methylotrophic metabolism. In Microbial Growth on $C_{1}$ Compounds, pp. 315-323. Edited by R. L. Crawford \& R. S. Hanson. Washington, DC: American Society for Microbiology.

Bartholomew, B., Dodgson, K. S. \& Gorham, S. G. (1978). Purification and properties of the S1 secondary alkylsulphohydrolase of the detergent-degrading microorganism Pseudomonas C12B. Biochemical Journal 169, 659-667.

Bateman, T. J., Dodgson, K. S. \& White, G. F. (1986). Primary alkylsulphatase activities of the detergent-degrading bacterium Pseudomonas $\mathrm{C} 12 \mathrm{~B}$. Purification and properties of the P1 enzyme. Biochemical Journal 236, 401-408.

Cloves, J. M., Dodgson, K. S., White, G. F. \& Fitzgerald, J. W. (1980). Purification and properties of the P2 primary alkylsulphohydrolase of the detergent-degrading bacterium Pseudomonas C12B. Biochemical Journal 185, 23-31.

Crescenzi, A. M. V., Dodgson, K. S. \& White, G. F. (1984). Purification and some properties of the D-lactate-2-sulphatase of Pseudomonas syringae GG. Biochemical Journal 223, 487-494.

Crescenzi, A. M. V., Dodgson, K. S., White, G. F. \& Payne, W. J. (1985). Initial oxidation and subsequent desulphation of propan-2-yl sulphate by Pseudomonas syringae GG. Journal of General Microbiology 131, 469-477.

Davies, I., White, G. F. \& Payne, W. J. (1990). Oxygen-dependent desulphation of monomethyl sulphate by Agrobacterium sp. M3C Biodegradation 1, 229-241.

Dijkstra, M., Frank, J., Jongejan, J. A. \& Duine, J. A. (1984). Inactivation of quinoprotein alcohol dehydrogenases with cyclopropane-derived suicide substrates. European Journal of Biochemistry 140, 369-373.

Dodgson, K. S. \& White, G. F. (1983). Some microbial enzymes involved in the biodegradation of sulphated surfactants. Topics in Enzyme and Fermentation Biotechnology 7, 90-155.

Dodgson, K. S., White, G. F. \& Fitzgerald, J. W. (1982). Sulfatases of Microbial Origin. Boca Raton: CRC Press.

Eatough, D. J., Lee, M. L., Later, D. W., Richter, B. E., Eatough, N. \& HANSEN, L. D. (1981). Dimethyl sulphate in particulate matter from coal- and oil-fired power plants. Environmental Science and Technology 15, 1502-1506.

Fox, B. G., Froland, W. A., Jollie, D. R. \& Lipscomb, J. D. (1990). Methane monooxygenase from Methylosinus trichosporium OB3b. Methods in Enzymology 188, 191-202.

Frank, J., van Krimpen, S. H., Verwiel, P. E. J., Jongejan, J. A., Mulder, A. C. \& Duine, J. A. (1989). On the mechanism of inhibition of methanol dehydrogenase by cyclopropane-derived inhibitors. European Journal of Biochemistry 184, 187-195.

GHISALBA, O. \& KUENZI, M. (1983). Biodegradation and utilization of monomethyl sulfate by specialized methylotrophs. Experientia 39, $1257-1263$

Ghisalba, O., Cevey, P., Kuenzi, M. \& Schar, H.-P. (1985a). Biodegradation of chemical waste by specialized methylotrophs, an alternative to physical methods of waste disposal. Conservation and Recycling 8, 47-71.

Ghisalba, O., Heinzer, F. \& KuenzI, M. (1985b). Microorganisms of the genus Hyphomicrobium and process for degrading compounds which contain methyl groups in aqueous solution. United States Patent no. 4492756.

Ghisalba, O., Schar, H.-P. \& Tombo, G. M. R. (1986). Applications of microbes and microbial enzymes in environmental control and organic synthesis. In Enzymes as Catalysts in Organic Synthesis. pp. 233-250. Edited by M. P. Schneider. Reidel Publishing Co.

Heiner, R. E., Konzak, C. F., Nilan, R. A. \& Bartels, H. (1962). Effect of temperature on in vitro and in vivo reactions of diethyl sulphate. Nature, London 194, 788-789.

Higgins, I. J., Best, D. J. \& Hammond, R. C. (1980). New findings in methane-utilizing bacteria highlight their importance in the biosphere and their commercial application. Nature, London 286, 561-564.

LARGE, P. J. (1983). Methylotrophy and Methanogenesis. Wokingham: Van Nostrand Reinhold.

Lee, M. L., Later, D. W., Rollins, D. K., Eatough, D. J. \& Hansen, L. D. (1980). Dimethyl and monomethyl sulfate: presence in coal fly ash and air borne particulate matter. Science 207, 186-188.

Lloyd, A. G., Tudball, N. \& Dodgson, K. S. (1961). Infra red studies on sulphate esters. III. O-Sulphate esters of alcohols, amino alcohols and hydroxylated amino acids. Biochimica et Biophysica Acta 52, 413-419.

Matcham, G. J. W., Bartholomew, B., Dodgson, K. S., Payne, W. J. \& FitzGerald, J. W. (1977a). Stereospecificity and complexity of microbial sulphohydrolases involved in the biodegradation of secondary alkylsulphate detergents. FEMS Microbiology Letters 1, 197-200.

Matcham, G. W. J., Dodgson, K. S. \& Fitzgerald, J. W. (1977b). Purification, properties and cellular location of the stereospecific CS2 secondary alkylsulphohydrolase of Comamonas terrigena. Biochemical Journal 167, 723-729.

Pilkington, S. J. \& Dalton, H. (1990). Soluble methane monooxygenase from Methylococcus capsulatus. Methods in Enzymology 118, 181-190.

Robinson, J. \& COOPER, J. M. (1970). Method of determining oxygen concentrations in biological media, suitable for calibration of the oxygen electrode. Analytical Biochemistry 33, 390-399.

SCHAR, H.-P. \& GHISALBA, O. (1985). Hyphomicrobium bacterial electrode for determination of monomethyl sulfate. Biotechnology and Bioengineering 27, 897-901.

Schar, H. P., Chemla, P. \& Ghisalba, O. (1985). Methanol dehydrogenase from Hyphomicrobium MS 223. FEMS Microbiology Letters 26, 117-122.

Shaw, D. J., Dodgson, K. S. \& White, G. F. (1980). Substrate specificity and other properties of the inducible $\mathrm{S} 3$ secondary alkylsulphohydrolase from the detergent degrading bacterium Pseudomonas C12B. Biochemical Journal 187, 181-190.

SHIMODA, M. \& OKURA, I. (1991). Selective inhibition of methanol dehydrogenase from Methylosinus trichosporium (OB3b) by cyclopropanol. Journal of Molecular Catalysis 64, L23-L25.

Thomas, O. R. T., MatTs, P. J. \& White, G. F. (1988), Localization of alkylsulphatases in bacteria by electron microscopy. Journal of General Microbiology 134, 1229-1236.

White, G. F. \& MATTS, P. J. (1992). Biodegradation of short-chain alkyl sulphates by a coryneform species. Biodegradation 3, 83-91.

White, G. F. \& Russell, N. J. (1993). Biodegradation of anionic surfactants and related compounds. In Biochemistry of Microbial Degradation, chapter 5. Edited by C. Ratledge. Dordrecht: Kluwer (in the Press). 